ISSN: 2689-9418

Volume 4, Issue 3, 2021 (pp. 139-165)

www.abjournals.org

\title{
DETERMINANTS OF NUTRITIONAL PRACTICES AMONG MOTHERS WITH UNDER-FIVE CHILDREN IS PARAMOUNT IN CURBING THE HIGH RATE OF MORBIDITIES AND MORTALITIES AMONG UNDER-FIVE CHILDREN
}

\author{
Dolapo Ogunmefun ${ }^{1}$, Olanrewaju Motunrayo F. (Ph.D) ${ }^{2}$ \\ ${ }^{1}$ Department of Public Health, Babcock University, Ilishan-Remo, Ogun State, Nigeria. \\ Email: femdop@gmail.com \\ ${ }^{2}$ Department of Public Health, Babcock University, Ilishan-Remo, Ogun State, Nigeria
}

Cite this article:

Dolapo O., Olanrewaju M.F. (2021), Determinants of Nutritional Practices Among Mothers with Under-Five Children is Paramount in Curbing the High Rate of Morbidities and Mortalities among Under-Five Children. African Journal of Health, Nursing and Midwifery 4(3), 139-165. DOI: 10.52589/AJHNMEWPLCHYM.

\section{Manuscript History}

Received: 10 April 2021

Accepted: 13 June 2021

Published: 20 June 2021

Copyright () 2020 The Author(s) This is an Open Access article distributed under the terms of Creative Commons AttributionNonCommercial-NoDerivatives 4.0 International (CC BY-NC-ND 4.0 ), which permits anyone to share, use, reproduce and redistribute in any medium, provided the original author and source are credited.

\begin{abstract}
Nutritional outcomes among under-five children in Nigeria are among the worst globally. Therefore, this study investigated the determinants of nutritional practices among mothers with under-five children attending selected primary health centers in Abeokuta, Ogun state, Nigeria. The study adopted a quantitative cross-sectional descriptive survey research design. A A multi-stage sampling technique was used to select 419 mothers of under-five children attending primary health centres in Abeokuta, Ogun State. All the Research questions and hypothesis were formulated and were tested using the SPSS version 27 to compute descriptive and inferential statistics which were tested at a 5\% level of confidence. The result indicated that mean age of respondents in this study was $28.48 \pm 5.811$ years with participants between the ages of 27-35 (44.6\%) were the highest. High level of knowledge regarding under-five nutrition was measured on a 21-points rating scale showed a mean score of 12.65 \pm 3.61 . There was good level of nutritional practices which was measured on a 17-points rating scale showed a mean score of 11.06 \pm 2.26 . There was a significant difference between level of education of mother and their nutritional practice $(P=0.000)$, there is a significant correlation between respondents' level of knowledge ( $r=0.256$; $p=0.000)$. In conclusion, the study established that there is good level of knowledge of under-five nutrition; there was poor support and good level of nutritional practice. The study recommended that continued training and re-training is very important for mothers of under-five children. There is also need for active involvement of the media in dissemination of nutritional benefits of under-five children.
\end{abstract}

KEYWORDS: Nutritional Practices, Mothers, Children, Morbidities, Mortalities, Nutritional Benefits 
ISSN: 2689-9418

Volume 4, Issue 3, 2021 (pp. 139-165)

www.abjournals.org

\section{INTRODUCTION}

The first 2-5 years of life are critical window to promote optimal child growth and development of the child, while good nutrition plays a major role in maintaining health and balance, malnutrition still remains a threat to under-five children. Malnutrition is a pathological state resulting from inadequate nutrition and broadly classified as undernutrition, as a result of insufficient intake of energy and other nutrients, and over-nutrition due to excessive consumption of energy and other nutrients (Awuchi, Igwe\&Amagwula, 2020). Nearly 12 million children <5years die each year in developing countries mainly from preventable causes, the death of over 6 million (55\%), are either directly or in directly attributable to under nutrition (Liu, Oza, Hogan, Perin, Rudan, Lawn et al., 2015). In Nigeria, malnutrition has, been reported to be associated with increased morbidity and mortality, such that $30-40 \%$ of death in the preschool age group are associated with malnutrition (Bashir \& Umar, 2012).

Nutritional outcomes among under-five children in Nigeria are among the worst globally (Fagbamigbe, Kandala\&Uthman, 2020). More than one third of children under five years of age in Nigeria are stunted, which represents about 9.7 million stunted Nigerian children in 2013 (Umeokonkwo, Ibekwe, Umeokonkwo, Okike, Ezeanosike\&Ibe, 2020). Likewise, approximately $18 \%$ of under-five children are wasted in the same year. The prevalence of child undernutrition is higher for less educated mothers, with about half of children of less educated mothers reported to be stunted in 2019 (Fadare, Amare, Mavrotas, Akerele\&Ogunniyi, 2019).

Additionally, the 2018 National Nutrition and Health Survey (NNHS) which was conducted by the National Bureau of Statistics (NBS), in collaboration with the National Population Commission (NPopC) and the Nigeria Federal Ministry of Health reported that the prevalence of underweight among children (0-59 months) in South West, Nigeria was $14.8 \%$. Similarly, it was reported that there was an increase in the rates of underweight among children in Abia, Ebony, Bayelsa, Benue, Delta, Ekiti, Enugu, Gombe, Ogun, Ondo, Plateau, Rivers and Yobe (Nutrition and Health Situation Nigeria, 2018; Gayawan, Adebayo, Komolafe\&Akomolafe, 2019). Studies also reported that the prevalence of underweight and stunting in Ogun State is $20.4 \%$ and $29.6 \%$ respectively among under-2 children compared to Oyo that shares boundary with Ogun State which is at $23 \%$ and $12.9 \%$ respectively (Otekunrin, Otekunrin, Sawicka\&Ayinde, 2020; Rhoda, Wagai, Beshanski-Pedersen, Yusafari, Sequeira, Hayford et al., 2020).

A study conducted in Abeokuta North LGA among children observed high prevalence of underweight, with $47 \%$ of the respondents mildly underweight, $13 \%$ moderately underweight, and 4\% were fund to be severely underweight (Adepoju\& Johnson, 2020). Generally, the risk of malnutrition in the first 2 years of life has been directly linked with poor breastfeeding and complementary feeding practices of mothers together with high rate of infectious diseases (Gebre, Reddy, Mulugeta, Sedik\&Kahssay, 2019).

Few studies have recognized components leading to stunting and wasting status of under-five children in Nigeria which includes inappropriate child feeding practices (Black, Allen, Bhutta, Caulfield, De Onis, Ezzat et al., 2008; Black, Victora, Walker, Bhutta, Christian, De Onis et al., 2013). Issues involving the personal-level predisposition of mothers'stem from factors such aspoor nutrition knowledge, poor attitude and lack of self-efficacy of mothers 
ISSN: 2689-9418

Volume 4, Issue 3, 2021 (pp. 139-165)

www.abjournals.org

with under-five children had been reported in literature as causes of child malnutrition and mothers' poor nutritional practices (Udoh\&Amodu, 2016; Vakili, Emami, Khademi, Vakili\&Saeidi, 2015). Similarly, research indicates that certain overlooked environmentallevel factors such as social-support from family members and significant others in the lives of nursing mothers also contribute to their poor nutrition practices and infant mortality (Walker CL, Rudan I, Liu L, Nair H, Theodoratou E, Bhutta et al., 2013; Fry-Bowers, Maliski, Lewis, Connell \&DiMatteo, 2014). Tette, Sifah and Nartey, (2015) opined that the lack of adequate knowledge regarding what constitutes good food, pre- and postnatal care and current immunization facilities for children is a major factor limiting adequate child nutrition. In addition, any damage caused by nutritional deficiencies in the early childhood is related to impaired cognitive development, poor educational achievement and low economic productivity (Akombi, Agho, Merom, Hall \&Renzaho, 2017).

Mothers should receive nutritional instructions and counsels during preconception, antenatal periods and postnatal periods and support, this are some of the many ways they will require assistance in order to have nutritional practices that will prolong the lives of their children (Berglund \&Lindmark, 2016; McInnes, Hoddinott, Britten, Darwent\& Craig, 2013). If they are not adequately equipped with skills regarding what to eat during the period preceding delivery, after delivery and how to respond to emerging child feeding situations that threaten the lives of their children, they will be weak in ensuring good nutritional status of their children.

To reduce under-fivechildren mortality, previous investigations have recognized the need for effective behaviour-change interventions targeting mothers (Elder, Pequegnat, Ahmed, Bachman, Bullock, Carlo et al, 2014). Past studies have indicated that behaviour-change on the part of mothers is critical in averting under-five children death and improving underfivechildren nutritional status (Fishbein, Bandura, Triandis, Kanfer, Becker, \&Middlestadt, 1992; Sulzer-Azaroff\& Mayer, 1992).

However, behaviour-change approaches should focus on improving information and comprehensionin order to enhance proper child nutritional practices (McInnes, Hoddinott, Britten, Darwent\& Craig, 2013). A number of studies have suggested thatmaternal education, family size, income, knowledge and social supportmay play significant roles as predictors of mothers with under-five children nutritional practices (Dereje, 2014; Oh, Kang, Cho, Ju\& Faye. 2019). However, these studies did not apply behaviour-change theories, hence, they did not provide the needed empirical evidence to support their claims. Most of these studies did not also link knowledge, attitude, behavioural skills and social support together as a combination of components that will improve and determine nutritional practices of mothers.

In this study, a model will be adapted to assess the personal and environmental-level factors affecting nutrition practices of mothers with under-five children. The PRECEDE (Predisposing Reinforcing and Enabling Construct in Educational/Environmental Diagnosis and Evaluation) Model (Green, Kreuter, Deeds \&Patridge, 1980) which suits the diagnosis of concern will be used as the conceptual guide to give the study an ecological outlook. This study therefore investigate determinants of nutritional practices among mothers with underfive children attending selected primary health centers in Abeokuta, Ogun state, Nigeria. 
ISSN: 2689-9418

Volume 4, Issue 3, 2021 (pp. 139-165)

\section{Research Objectives}

The broad objective of this study was to investigate the determinants of nutritional practices among mothers with under-five children attending selected primary health centers in Abeokuta, Ogun state, Nigeria. The specific objectives are to:

1. determine the level of personal predisposing factors such as socio-economic characteristics, nutritional knowledge, and attitude towards nutrition by mothers with under-five children attending PHCs in Abeokuta.

2. Determine the level of environmental reinforcing factors such as social-support received by mothers with under-five children attending PHCs in Abeokuta towards nutrition.

3. assess the level of self-efficacy of mothers with under-five children attending PHCs in Abeokuta.

4. determine the nutritional practices of mothers with under-five children attending PHCs in Abeokuta.

\section{Research Questions}

1. What is the level of personal predisposing factors such as socio-economic characteristics, nutritional knowledge and attitudetowards nutrition by mothers with under-five children attending PHCs in Abeokuta?

2. What is the level of environmentalreinforcing factors such as social-support received by mothers with under-five children attending PHCs in Abeokuta towards nutrition?

3. What is the level of self-efficacy of mothers with under-five children attending PHCs in Abeokuta?

4. What is the nutritional practices of mothers with under-five children attending PHCs in Abeokuta?

\section{Research Hypotheses}

This study hypothesized the following:

1. There is a significant relationship between educational status and nutritional practice of respondents.

2. There is a significant association between nutrition knowledge and practice of respondents.

3. There is a significant relationship between social support and nutrition practice of respondents. 


\section{METHODS AND DESIGNS}

\section{Research Design}

The studywas a quantitative study, cross-sectional survey research design. The study will enable the testing of the statistical hypothesis and gives explanations and analysis by examining the statistical associations between variables that would be gathered during the survey. The sample of mothers of under-five children will represent the population of interest. The survey will address the research questions and thereby provided ways of attaining the research objectives.

\section{Population}

The study population would include mothers of under-five children who registered their infants in the Primary Health centers of interest attending Primary Health Centers in Abeokuta for postnatal care during the period of the survey.

\section{Inclusion Criteria}

Those that would be considered for inclusion in the study are:

1. Mothers who had one or more infants attending immunisation sessions in selected Primary Health Centre during the survey.

2. Mothers whose children (<5years) are receiving immunisation in selected Primary Health Centre during the surveyand agreed to partake in the study.

3. Mothers who came for post-natal care sessions at the selected Primary Health Centre during the survey.

\section{Exclusion Criteria}

Those that would be considered for exclusion from the study are:

1. Mothers whose infants attended the selected Primary Health Centre during the surveybut disagreed to partake in the study.

2. Pregnant women who attended the selected Primary Health Centre during the surveybut are not currently nursing any infant.

\section{Study Area}

Ogun State was created on the 3rd of February, 1976. It was carved out of the old Western State of Nigeria and named after the Ogun River which runs across it from North to South. Situated between Latitude $6.20 \mathrm{~N}$ and $7.80 \mathrm{~N}$ and Longitude $3.0 \mathrm{oE}$ and $50 \mathrm{E}$, the state covers a total landmass of $16,409.26 \mathrm{sqkm}$. Abeokuta, the capital and largest urban center, is about 90 kilometers from Lagos and 740 kilometers from Abuja, the capital of Nigeria. The State is strategically located, bordered in the East by Ondo State, in the North by Oyo and Osun States and in the South by Lagos State and the Atlantic Ocean and in the West by Republic of Benin, which makes it an access route to the expansive markets of the Economic Community of West African States (ECOWAS). There are twenty local government areas in this state. 
ISSN: 2689-9418

Volume 4, Issue 3, 2021 (pp. 139-165)

www.abjournals.org

The State's total projected population was 7.1 million people as of 2014. The population is largely made of young people with $42.54 \%$ between the ages of $0-14$ years.Its people are very industrious and are found in all works of life. The State is a major economic hub. It has one of the largest concentration of industries in the country and serves as the major corridor for transportation of goods, services and people between the nation's commercial center Lagos, the rest of the country and West Africa at large.

\section{Description of Study Settings}

This study was conducted in Abeokuta North local government area (ANLGA) situated in Abeokuta, Ogun state, Nigeria. The LGA has a total land area of 723.80 square kilometers and an estimated population of 210,940 (Census 2006, Bureau of Land and survey, Ogun State Government) with the population of child bearing women (15-49 years) at 51,203 as at the 2006 census. The ANLGA is bounded on the North by Odeda LGA, on the West by Yewa North LGA, on the South by Ewekoro LGA and on the east by Abeokuta South LGA. It has its local government mainly inhabited by the Egbas who are the EgbaEku,Egba Arin and the EgbaIgbeyin with its headquarters at Akomoje. The people are predominantly farmers, most of whom engage in cultivation of arable crop, while some engage in livestock and fishing. In recent times, the people of the area are involved in quarry business, artisan works, and handicrafts such as tie and dye making and pottery.

There are about 22 functional health facilities (both private and public) in the LGA. There are two tertiary health institutions (Federal Neuropsychiatric Hospital, Aro, and OlabisiOnabanjo Teaching Hospital, Saje Annex) and six primary health centers in the LGA. There are also many private hospitals and maternity homes. The antenatal clinics in the health facilities are run by doctors and nurses. There are consultant Obstetricians and Gynaecologists, resident doctors, and medical officers in some of these hospitals especially the teaching hospitals. Each primary health center is run by nurses and a doctor but there are few centers without a doctor. The private maternity homes are run by nurses, traditional birth attendants, and community health extension workers (CHEW). Each health facility has fixed days for their ANC service. Doctors and nurses run antenatal clinics where comprehensive obstetric care is offered such as caesarian sections, ultrasonography, and blood transfusion service. Health education is also offered.

\section{Sample size and sampling Technique}

The sample size was determined using Cochran's alpha formula for computation of sample size (1963):

$$
\mathrm{Z} \alpha(\mathrm{N})=\frac{\mathrm{Z}^{2} \mathrm{~S}^{2}}{\mathrm{~d}^{2}}
$$

$\mathrm{WhereS}^{2}=\mathrm{P}[1-\mathrm{P}]=\mathrm{PQ}$

$$
\begin{aligned}
& Z^{2}=1.96^{2}, \\
& P=0.5 \\
& Q=0.5,
\end{aligned}
$$


ISSN: 2689-9418

Volume 4, Issue 3, 2021 (pp. 139-165)

$$
\begin{gathered}
\mathrm{d}^{2}=0.05^{2} \\
\mathrm{~S}^{2}=\mathrm{PQ}, \quad \mathrm{N}=\underline{\mathrm{Z}^{2} \mathrm{PQ}} \\
\mathrm{d}^{2}
\end{gathered}
$$

Therefore, $=\underline{1.96^{2} \times 0.5 \times 0.5}$

$$
0.05^{2}
$$

$=384.16$

The minimum sample size was 384 .

$10 \%$ of the minimum sample size was added to take care of attrition.

The total number of participants after adding $10 \%$ of 384 was $=38.41+384.16=422.57$

Approximately 423 participants were considered for the study.

A multi-stage sampling technique would be used to select the participants for the study accordingly:

-There are two local government area in Abeokuta; which are Abeokuta North and Abeokuta South local government area. Purposive Sampling technique was used to select Abeokuta North LGA due to its population and large number of PHCs in the location compared to the other LGA.

- Secondly, there are 16 wards (health) in Abeokuta North LGA, three wards was selected by simple random sampling. The 16wards in Abeokuta North Local government area are stated below which includes

1. Iberekodo 1

2. Iberekodo 2

3. Iberekodo 3

4. Iberekodo 4

5. Iberekodo 5

6. Totoro I

7. Totoro ii

8. Sabo I

9. Sabo ii

10. Totoro iii

11. Totoro iv 
ISSN: 2689-9418

Volume 4, Issue 3, 2021 (pp. 139-165)

12. Idiya

\section{Olorunda}

14. Imala Idi-emi

15. Ikereku I

16. Ikereku ii

Three wards randomly selectedare Idiya, Iberekodo ward 5, and Sabo ward ii

The third stage, a list of the registered PHC providing post-natal care was obtained from the Local Government Health office. Iberekodo,Sabo, and AdeunHealth Centers are the Primary Health facilities that were selected by simple random sampling from each pre-selected ward and proportional sampling method was used to distribute the questionnaire among the three pre-selected Primary Health Centers. Population for the three pre-selected PHCs are 26,$983 ; 27,503$ and 28,112respectively, hence total population was divided in proportion 1:2:3

$(1 / 6 \times 423 / 1)+(2 / 6 \times 423 / 1)+(3 / 6 \times 423 / 1)=$

$71+141+211=$

Total $=423$

Therefore 71, 141, and 211 questionnaires were distributed using convenience sampling technique to eligible and willing participants at Iberekodo,Sabo and AdeunPHCS respectivelyover a period of four weeks, at the study location.

\section{Study variables and Test of Null Hypotheses}

\section{Study Variables}

\section{Independent Variables}

The independent variables that were considered in the instrument to assess the participants were as follows:

Section A: Demographic and Socio-economic characteristics of mothers with under-five children attending PHC in Abeokuta South LGA. This variable consisted of the age of the mother, her marital status, her occupational status, educational status,religion, household size, household income, family structure, socio-economic status.

Section B: Nutritional knowledge of mothers with under-five children which consisted of 21items with the multiple-choice response format. The variable would be measured on a 21point rating scale.

Section C: Level of attitudes of mothers withunder-five children to their nutritional practiceswhich consisted of 4-items with 4 option Likert-type response format (Strongly Agreed, Agreed, Disagreed and Strongly Disagreed). The variable was measured on a 12point rating scale. 
ISSN: 2689-9418

Volume 4, Issue 3, 2021 (pp. 139-165)

www.abjournals.org

Section D: level of support mothers with under-five children receive to practice proper nutrition which consisted of 5-items with 4 option Likert-type response format (Never, Rarely, Occasionally, Always). The variable was measured on a 15-point rating scale.

Section E: Level of Self-efficacy of mothers with under-five children to practice proper nutrition which consisted of 9-items with 4 option Likert-type response format (Strongly Agreed, Agreed, Disagreed and Strongly Disagreed). The variable was measured on a 17point rating scale.

\section{Dependent variable}

The dependent variable in the instrument used to retrieve data for the study was contained in Section F (Nutritional Practices of mothers withunder-five children). This section consists of 6-items with the dichotomous-type response format and 11-items with the multiple-choice response format.The variable was measured on a 17-point rating scale.

\section{Test of Null Hypotheses}

The following null hypothesis will be tested to validate the research hypotheses:

1. Ho: There is no significant relationship between educational status and nutritional practice of respondents.

2. Ho: There is no significant association between nutritional knowledge and nutritional practice of respondents

Decision rules would be set at $5 \%$ level of significance. Therefore, when the test is conducted, P Values greater than $5 \%$ will be rejected.

\section{Instrument for Data Collection}

Semi-structured questionnaire was developed for data collection during this study. The variables were aligned in a way that they would match with the research objectives thereby giving answers to the research questions. The variables contained relevant items strategically structured for easy and accurate computation. The instrument was drafted in English language and the instrument was questionnaire. It was interviewer administered to the illiterates, while the literate was Self-administered.

Section A: Demographic and Socio-economic characteristics of mothers with under-5 children attending PHCs in Abeokuta North LGA. This variable consisted of the age of the mother, her marital status, her occupational status, her religion, household size, household income, family structure, socio-economic status, no of antenatal and postnatal attendance.

Section B: Nutritional knowledge of mothers withunder-five children which consisted of 21items with the multiple-choice response format. The variable was measured on a 21-point rating scale.

Section C: Level of aattitudes of mothers with under-five children to their nutritional practices which consisted of 4-items with 4 option Likert-type response format (Strongly Agreed, Agreed, Disagreed and Strongly Disagreed). The variable was measured on a 12point rating scale. 
ISSN: 2689-9418

Volume 4, Issue 3, 2021 (pp. 139-165)

www.abjournals.org

Section D:Level of support mothers with under-five children receive to practice proper nutrition which consisted of 5-items with 4 option Likert-type response format (Never, Rarely, Occasionally, Always). The variable was measured on a 15-point rating scale.

Section E: Level of Self-efficacy of mothers with under-five children to practice proper nutrition which consisted of 9-items with 4 option Likert-type response format (Strongly Agreed, Agreed, Disagreed and Strongly Disagreed). The variable was measured on a 17point rating scale.

\section{Validity and Reliability of Instrument}

\section{Validity}

To ensure the validity of the instrument, the following criteria were carefully looked into:

1. Face validity:This was done by the researcher's supervisor and by lecturer's in the department and public health nutritionist.

2. Item validity: The items were carefully and thoughtfully prepared and arranged in order for them to align with each of the variables they fell under which made them coherent with the variables. It was done by using Alpha Cronbach coefficient. Alpha Cronbach score for section B was 0.751, C - 0.723, D- 0.704, E-0.702, F-0.732.

3. Construct validity: During the study, it was ensured that the conceptual framework adopted as behaviour-change model was appropriate to the study and the variables in the instrument were selected from the model used. This was done by ensuring that sections in the instrument was aligned in the construct of the PRECEDE contextual framework.

\section{Reliability}

To ascertain the reliability of the instrument, a pilot-test was first conducted for internal consistency of the instrument using $10 \%$ of the projected sample size (40 nursing mothers) from Sagamu primary health centre. Thereafter, a test re-test was conducted for reliability of the instrument also using $10 \%$ of the anticipated sample size (40 nursing mothers) also from Sagamu Primary health centre. It was ensured that the sample for both the pilot-test and testretest had the same characteristics as the study population (nursing mothers with infants).

The data from the test-retest was statistically analysed using Cronbach alpha standard score to test its reliability. Hence, a Cronbach alpha score of 0.738 was obtained which ensured the reliability of the instrument. Necessary corrections were made where required in the items after the test-retest. This took care of the initial weakness of the instrument and ensured it was reliable enough to assess the situation of concern.

\section{Method of Data Collection}

The health office at Abeokuta North local Government was visited earlier in order to get information for the ease of data collection and to seek for permission from the authorities. The primary health centres included in this study were visited afore hand in order to sensitize the heads of each of the facilities about the study. This aidedeasy entry into the health 
ISSN: 2689-9418

Volume 4, Issue 3, 2021 (pp. 139-165)

www.abjournals.org

facilities and give room for the health workers in these facilities to address the nursing mothers about the study.

Four research assistants were employed, trained on how to administer instruments in approachable and pleasant manners and allowed to go through the instrument for clarity. After the healthcare personnel in each hospital approved that the study can be carried out in their facility, the nursing mothers were briefed about the purpose of the study and their consents sought too. The prepared instrument was then administered to each of the participants by the researcher and the research assistants. Required data filled in as appropriate by the participants and collected by the researcher and research assistants. Data was collected over a period of 4 weeks. The health centres were visited for data collection according to the days they opened for immunisation of infants and post-natal care. Research assistance were appreciated with a token after each session of data collection.

\section{Method of Data Analysis}

Data derived from completed instrument was computed and analysed using Statistical Package for Social Science (SPSS) version 21.0. Frequency distribution was computed to record responses from respondents on all items in the instrument. The variables werecomputed and responses transformed into rating scales to derive summaries of descriptive statistics such as means, standard errors of means and standard deviation. Correlation and linear regression analysis wad conducted to give statistical responses to the research questions and hypotheses. Through regression analysis also, comparison was drawn between those with good self-reported infant-survival practices and those with poor scores in order to identify how predictor variables function. Analysis Of Variance (ANOVA) would be evaluated to assess how demographic data influenced responses of participants and to compare their responses based on demographic characteristic

\section{RESULT}

\section{Socio-demographic Characteristics of Respondents}

The mean age of respondents in this study was $28.48 \pm 5.811$ years with participants between the ages of 27-35 (44.6\%) were the highest, followed by respondents between the ages of 18$26(42.2 \%)$ while the least represented age group was respondents below the age of 18 at $0.5 \%$ in the study. About $(86.6 \%)$ of the respondents were married, $7.9 \%$ single, $4.5 \%$ separated while $1 \%$ were widow. In terms of occupational status, interestingly, about $(8.1 \%)$ of the respondents were unemployed, $65.9 \%$ were self-employed, $17.2 \%$ civil servants/private organization, housewives were $8.6 \%$ and $2 \%$ were retired. Most of the respondents in this study were Christian (65.9\%), Islam 32\% and Traditionalist at $2.1 \%$ respectively. For ethnicity, Yoruba was reported as the leading ethnic group with $89.7 \%$, Igbo $6.9 \%$, Hausa $2.6 \%$, and others at $0.7 \%$ (See Table 4.1a).

A chronicle of $5 \%$ of the respondents had no formal education, $15.5 \%$ had primary school education, about $54.9 \%$ had secondary school education and $24.6 \%$ with tertiary level education, respectively. Also, 23.2\% attended antenatal care sessions once, (54.2\%) attended two times, $19.3 \%$ attended three times, $2.9 \%$ attended four times and only $0.5 \%$ attended antenatal care sessions five times before giving birth (See Table 4.1a). More than half of the 
ISSN: 2689-9418

Volume 4, Issue 3, 2021 (pp. 139-165)

www.abjournals.org

respondents $(64.7 \%)$ attended post-natal care sessions once, a total of $27.7 \%$ attended twice, $6.7 \%$ attended thrice, $0.7 \%$ attended four times and only $0.2 \%$ attended five times (See Table 4.1b).

Interestingly, about $52.5 \%$ had their deliveries at the hospital while $34.1 \%$ at health centers and $13.4 \%$ had theirs at home. Approximately, 33.9\% of the respondents have one child each alive, about $39.9 \%$ have two children each, while $26.3 \%$ have more than two children alive (See Table 4.1b).

Practically $74.9 \%$ of the respondents had never lost any of their infants, approximately $16.5 \%$ of them had lost one child each, $7.6 \%$ had lost two children each and $1 \%$ had lost more than two each. Just about $27.4 \%$ of the respondents had a household size of less than 3 , while about $54.2 \%$ with a household size of $3-6$, and $16.2 \%$ of them had a household size of 7-10, also $2.1 \%$ with a household size of 10 or more. For the father's occupation, about $17.2 \%$ were government workers, $42.2 \%$ of them were private workers, $31.7 \%$ were business owners, $4.85 \%$ were artisans, $1.9 \%$ without were without jobs (See Table $4.1 b$ ).

Interestingly, about $26.5 \%$ of the respondents in this study earn less than 10,000 naira monthly, $29.6 \%$ earn 10,001 to 20,000 monthly, $16.7 \%$ earn 20,0001 to 30,000 monthly, $4.3 \%$ earn 30,0001 to $40,000,7.9 \%$ earn 40,0001 to 50,000 and about $15 \%$ earn more than 50,000 as their monthly income respectively (See Table $4.1 \mathrm{~b}$ ). Fascinatingly, about $30.1 \%$ of respondents in this study earn less than 10,000 as household income. About $18.9 \%$ earn 10,001 to $20,000.15 .8 \%$ earn 20,001 to $30,000,8.6 \%$ earn 30,0001 to 40,000 , about $9.1 \%$ earn 40,0001 to 50,000 and just about $17.7 \%$ earn more than 50,000 categorically (See Figure 4.1). A total of $28.9 \%$ of the respondents of this study were in the upper class, $37 \%$ of them were in the middle class and $34.1 \%$ were in the lower class (See Figure 4.2).

Similarly, about $86.4 \%$ of the respondents went through normal delivery and roughly $13.6 \%$ went through caesarean session of delivery during the birth of their last child (See Figure 4.3). The family structure of the respondents of this study was represented viz; monogamous $(67.1 \%)$, polygamous $(18.1 \%)$ and single (14.8\%), respectively (See Figure 4.4).

Table 1: Socio-demographic Characteristics of the Respondents

Socio-demographic variables for consideration

Age $($ in years) mean age $=\mathbf{2 8 . 4 8} \pm \mathbf{5 . 8 1 1}$

Below 18

$18-26$

$27-35$

$36-44$

Above 45

Marital Status

Single

Married

Separated

Widowed
Frequency(419) Percentage(\%)

2

0.5

177

42.2

187

44.6

47

11.2

6

1.4

33

363

7.9

19

86.6

4
4.5

1 
African Journal of Health, Nursing and Midwifery

ISSN: 2689-9418

Volume 4, Issue 3, 2021 (pp. 139-165)

\section{Occupational status}

Unemployed

Self-employed

Civil servant/Private organisation

Housewife

36

8.6

Retired

1

2

Religion

Christianity

Islam

134

32

Traditional

9

2.1

Ethnicity

Yoruba

Igbo

Hausa

Others

3

0.7

Educational attainment

No formal education

$21 \quad 5$

Primary school

Secondary school

Tertiary level

How many antenatal care sessions did you attend?

One

Two

Three

Table 2: Socio-demographic Characteristics of the Respondents

\section{Socio-demographic variables for consideration}

How many post-natal care sessions have you attended

One

Frequency(419) Percentage(\%)

Two

Three

116

27.7

Four

28

6.7

Five

3

0.7

Place of delivery of your last child

$1 \quad 0.2$

At home

At health center

At hospital

Number of Children alive

one child 
African Journal of Health, Nursing and Midwifery

ISSN: 2689-9418

Volume 4, Issue 3, 2021 (pp. 139-165)

www.abjournals.org

More than two

110

26.3

Number of infants you have ever lost

none

$314 \quad 74.9$

one child

69

16.5

Two children

$32 \quad 7.6$

More than two

4

1

What is your Household size?

less than 3

115

27.4

$3-6$

227

54.2

7- 10

68

16.2

10 or more

9

2.1

What is the father's occupation?

Government worker

Private worker

72

17.2

Business owner

177

42.2

Artisan

133

31.7

Not working

$20 \quad 4.8$

Others

$8 \quad 1.9$

92.1

What is your income

Less than 10,000

111

26.5

$10,001-20,000$

124

29.6

20,001-30,000

70

16.7

$30,0001-40,000$

18

4.3

40,0001- 50,000

33

more than 50,000

63

7.9

15

\section{Respondents Level of nutritional knowledge (personal-level predisposing factors)}

The column shows the statistics of the personal-level predisposing factors of the mothers with under-five children, in terms of nutritional knowledge. When respondents were asked what they understood as 'Balanced Diet', precisely $29.6 \%$ chose wrong options while good number of participants $(70.4 \%)$ answered correctly. From this study, it can be deduced that $83.5 \%$ of the respondents know correctly why normal nutrition is necessary for children. Also, a total of $91.6 \%$ knows correctly the factors that influence protein energy malnutrition, while $44.9 \%$ do not know the causes of protein energy malnutrition in under-five children (See Table 4.2a).

Furthermore, about $34.1 \%$ of the participants were able to correctly tell how to identify energy (carbohydrate) deficiency in children. When asked 'when a baby should be put to breast', a total of $51.1 \%$ of the respondents accurately answered the question. Additionally, $49.4 \%$ of the participants could tell correctly what the first feed of a baby should be while more than half $(57.3 \%)$ of the respondents do not know what colostrum is (See Table 4.2a). Similarly, when asked what 'weaning' is, only about $53.9 \%$ of the respondents could give accurate answers. It can be deduced from the statistics used in this study that only $66.6 \%$ of the respondents know the type of supplementary feeding to be given to a 6-month old child (See Table $4.2 \mathrm{a}$ ). In the same vein, precisely $70.6 \%$ know what precautionary steps to take 
ISSN: 2689-9418

Volume 4, Issue 3, 2021 (pp. 139-165)

www.abjournals.org

while preparing supplementary food, however, only about $39.6 \%$ could state correctly how to preserve nutritive value of cereals while cooking (See table $4.2 \mathrm{~b}$ ).

A total of $67.3 \%$ could justly tell the causes of diarrhea in children and only $23.4 \%$ of the participants know what age solid foods can be introduced to children. Precisely $64.4 \%$ of the study participants knows correctly the groups of food combination that can keep a child healthy while about $70.2 \%$ could justly tell how cereals were helpful to children. Similarly, $77.1 \%$ of the participants justly stated how vegetables was helpful to child's diet, also $84.7 \%$ participants could rightly state how well to manage diarrhea in infants. When asked 'how long the child should be on exclusive breastfeeding $57.8 \%$ accurately answered and $42.2 \%$ gave either wrong answers or a combination of right and wrong answers which implies they have little knowledge on how long a child should be on exclusive breast feeding (See table $4.2 b)$.

The respondent level of knowledge regarding under-five nutrition was measured on a 21points rating scale showed a mean score of 12.65 \pm 3.61 translated to level of nutritional knowledge prevalence of $60.2 \%$ (See Table 4.13). The proportion of respondents with low level of nutritional knowledge is about $7.6 \%$ (See Table 4.3). One can infer that the respondents had a moderate-to-high level of under-five nutritional knowledge.

Table 2: Mothers with Under-five children NutritionalKnowledge

\begin{tabular}{|c|c|c|}
\hline Items & $\begin{array}{l}\text { Frequency } \\
(419)\end{array}$ & $\begin{array}{l}\text { Percentage } \\
(\%)\end{array}$ \\
\hline \multicolumn{3}{|c|}{ What do you understand by the term "BalancedDiet"? } \\
\hline 1. Correct response & 295 & 70.4 \\
\hline 2. Wrong responses & 124 & 29.6 \\
\hline \multicolumn{3}{|c|}{ Why is normal nutrition necessary for thechildren? } \\
\hline 1. Correct response & 350 & 83.5 \\
\hline 2. wrong responses & 69 & 16.5 \\
\hline \multicolumn{3}{|c|}{$\begin{array}{l}\text { Which are the following factors that influences PEM in } \\
\text { under fivechildren? }\end{array}$} \\
\hline 1. Correct response & 384 & 91.6 \\
\hline 2. wrong responses & 35 & 8.4 \\
\hline \multicolumn{3}{|c|}{ Which is the main cause for PEM in under fivechildren? } \\
\hline 1. Correct response & 231 & 55.1 \\
\hline 2. wrong responses & 188 & 44.9 \\
\hline \multicolumn{3}{|c|}{$\begin{array}{l}\text { How will you identify energy (Carbohydrate) deficiency } \\
\text { inChildren? }\end{array}$} \\
\hline 1. Correct response & 143 & 34.1 \\
\hline 2. wrong responses & 276 & 65.9 \\
\hline \multicolumn{3}{|c|}{ How will you identify Protein deficiency inChildren? } \\
\hline 1. Correct response & 322 & 76.8 \\
\hline 2. wrong responses & 97 & 23.2 \\
\hline \multicolumn{3}{|c|}{ When should a baby be put tobreast? } \\
\hline 1. Correct response & 214 & 51.1 \\
\hline 2. wrong responses & 205 & 48.9 \\
\hline \multicolumn{3}{|c|}{ What should be the first feed for thebaby? } \\
\hline
\end{tabular}


ISSN: 2689-9418

Volume 4, Issue 3, 2021 (pp. 139-165)

www.abjournals.org

1. Correct response

212

50.6

2. wrong responses

What do you mean bycolostrum?

179

42.7

1. Correct response

2. wrong responses

What do you mean byweaning?

1. Correct response

2. wrong responses

What type of supplementary feeding is to be given to the child at the age of six months?

1. Correct response

2. wrong responses

Table 3: Mothers with Under- children Nutritional Knowledge

Items

\section{Frequency Percentage \\ (419) \\ (\%)}

What precautions will you take while preparing supplementaryfood?

1. Correct response

$296 \quad 70.6$

2. wrong responses

123

29.4

How do you preserve nutritive value of cereals whilecooking?

1. Correct response

2. wrong responses

What are the causes for diarrhoea inchildren?

1. Correct response

2. wrong responses

At what age should solid food should beintroduced?

1. Correct response

2. wrong responses

From the following groups of food which combination can keep a childhealthy?

1. Correct response

2. wrong responses

How are cereals helpful tochildren?

a. Correct response

b. wrong responses

What are the main sources of protein (body buildingfood)?

a. Correct response

b. wrong responses

a. Correct response

b. wrong responses 


\begin{tabular}{lll}
\hline How will you manage diarrhoea ininfant? & 64 & 15.3 \\
$\quad$ a. Correct response & & \\
b. wrong responses & 242 & 57.8 \\
How long should the child should be on exclusive & 177 & 42.2 \\
breastfeeding? & & \\
1. Correct response & & \\
2. wrong responses & & \\
\hline
\end{tabular}

Table 3: Proportion of the Respondents' nutritional knowledge

\begin{tabular}{lll}
\hline & Frequency $(\mathbf{N}=\mathbf{4 1 9})$ & Percentage\% \\
Low & 32 & 7.6 \\
Moderate & 234 & 55.8 \\
High & 153 & 36.5 \\
\hline
\end{tabular}

\section{Respondents Nutritional Practices}

More than $50 \%$ of the respondents introduced breastfeeding within 1 hour after deliverywhile about $14.3 \%$ of them did so after 24hours (See Table 4.10a). Also 50.6\% gave their under-6 months' age child water, herbs and soft, however three quarter $(75.3 \%)$ of the respondents breastfeed on demand (See Table 4.10a). Half (54.4\%) of the respondents breastfeed their children for 6months before the addition of other food while $32.5 \%$ breastfeed above 6months. Averagely (52.7\%), breastfeed their baby alongside with complementary foods while $60.9 \%$ include varieties of food including fruits and vegetables in their child's complementary foods (See Table 4.10a).

Half (54.4\%) of the study participants introduce complementary foods to their infants at 6 months while $12.4 \%, 11.9 \%, 13.4 \%, 2.6 \%, 5.3 \%$ introduce complementary foods to their infants at $<4$ months, $4-5$ months, 7 months, 8 months and 12 months respectively (See Table 4.10a). Similarly, $21.7 \%$ feed their child with complementary foods once per day while $32.2 \%$ and $27.7 \%$ feed them 2-3times and 4-5times daily with complementary food (See Table $4.10 \mathrm{~b})$. Three quarter $(80.2 \%)$ of the respondents receive vitamin A supplement for their child at 6 months and also include varieties of food in their child's diet (See Table $4.10 \mathrm{~b})$. More than half $(69.5 \%)$ of the study participants add salt to their child's food while an average (54.4\%) number of them also feed their child with bowl and spoon (See Table $4.10 \mathrm{~b}$ ). Over $90 \%$ of the respondents always wash their hands before feeding your child and also wash and sterilize feeding utensils after use (See Table 4.10b)

The participant in this study level of nutritional practiceswas measured on a 17-points rating scale showed a mean score of $11.06 \pm 2.26$ translated to practice prevalence of $65.1 \%$ (See Table 4.13). The proportion of respondents with high nutritionalpractice is $86.9 \%$ (See Table 4.11). One can infer that majority of the respondents practice proper nutrition for their underfive children. 
ISSN: 2689-9418

Volume 4, Issue 3, 2021 (pp. 139-165)

Table 4: Mother's with under-five children Nutritional Practices

\section{Items}

In respect to your last child what time did you introduced breastfeeding?

1. Within 1 hour

2. Within 8 hour

3. Within 24 hour

4. 24hours after birth

Do you give water, herbs and soft drinks to your child less than 6 months?

1. Yes

2. No

How many times do you breastfeed your child in a day

1. 2 times

2. 3 times

3. On demand

4. >3 times

How long do you breastfeed your child before the addition of other food?

1. <4 months

2. 5 months

3. 6months

4. Above 6 months

Do you breastfeed your baby alongside with complementary foods
1. Yes
2. No

Do you include varieties of food including fruits and vegetables in your child complementary foods?

1. Yes

2. No

In respect to your last child what time did you introduce complementary foods?

1. <4 months

Frequency

(419)

251

96

60

12

212

207

49.4

10

2.4

62

315

32

14.8

75.2

7.6

2.9

centage

$\%)$

\section{4}

5.7

31

7.4

228

54.4

136

32.5

221

52.7

198

47.3

255

60.9

164

39.1

2. 4-5 months

52

12.4

50

11.9

228

54.4

3. At 6 months

56

13.4

4. 7 months

5. 8 months

22 
African Journal of Health, Nursing and Midwifery

ISSN: 2689-9418

Volume 4, Issue 3, 2021 (pp. 139-165)

www.abjournals.org

Table 5: Mother's with under-five children Nutritional Practices

Items

How frequent do you fed your child with complementary foods per day?

1. Once

2. 2-3 times

3. 4-5 times

4. 6-7 times

5. 8-12 times

Did your child receive vitamin A supplement at 6 months?

1. Yes

2. No

Do you include varieties of food in your child diet
1. Yes

2. No

Do you add salt to your child's food?

1. Yes

2. No

What do you use to feed your child?

1. Feeding bottle

2. Bowl and spoon

3. Hand feeding

Describe the thickness of your child's food?

1. Same as other people in the family

2. Thick enough to stay on a spoon

3. Watery, similar to breast milk

Do you wash your hands before feeding your child?

1. Sometimes

2. Always

3. Never

Do you wash and sterilize feeding utensils after use?

Correct response

1. Sometimes

2. Always

3. Never

\section{Frequency Percentage}

(N)

(\%)

91

21.7

135

32.2

116

27.7

56

13.4

21

5

336

80.2

83

19.8

313

74.7

106

25.3

291

69.5

128

30.5

178

42.5

228

54.4

13

3.1

$66 \quad 15.8$

$206 \quad 49.2$

$147 \quad 35.1$

$\begin{array}{ll}27 & 6.4\end{array}$

$383 \quad 91.4$

$9 \quad 2.1$

$\begin{array}{ll}24 & 5.7\end{array}$

$388 \quad 92.6$

$\begin{array}{ll}7 & 1.7\end{array}$ 
African Journal of Health, Nursing and Midwifery

ISSN: 2689-9418

Volume 4, Issue 3, 2021 (pp. 139-165)

www.abjournals.org

Table 6: Proportion of the Respondents' nutritional practice

\begin{tabular}{lll}
\hline & Frequency $(\mathbf{N}=\mathbf{2 4 5})$ & Percentage\% \\
Low & 55 & 13.1 \\
High & 364 & 86.9 \\
\hline
\end{tabular}

Information on the age certain foods were introduced by mothers to their under-five children.

There is a propensity that the information gotten from the respondents in this study about the ages certain foods were introduced during nursing would spur exciting controversies. About $2.4 \%$ of the respondents introduced cereals (rice, pap, bread, semo) at less than 3 months, $3.6 \%$ at 3-5 months, about $39.1 \%$ at 6 months, $47.3 \%$ did at 6 months to 1 year and precisely $7.6 \%$ introduced these foods after 1 year. Interestingly, $0.5 \%$ introduced yam and other tubers at less than 3 months, $0.3 \%$ at 3-5 months, $31.0 \%$ at 6 months, $48.2 \%$ at 6 months to 1 year, and $48.2 \%$ did after 1 year. Fruits and vegetables were introduced viz; $0.7 \%$ at less than 3 months, $1.7 \%$ at $3-5$ months, $31.7 \%$ at 6 months of age, $52.5 \%$ at 6 months to 1 year and $48.2 \%$ after 1 year. A total of $0.7 \%$ introduced legumes/beans at less than three months, $2.4 \%$ did at 3-5 months, about 34.6\% at 6 months, $55.4 \%$ at 6 months to 1 year and $6.9 \%$ after 1 year. Precisely $9.3 \%$ introduced fish/meat/egg after 1 year of nursing, a total of $55.4 \%$ at 6 months to 1 year, $32.2 \%$ introduced at 6 months, $2.6 \%$ at $3-5$ months, and $0.5 \%$ at less than 3 months. A total of $0.5 \%$ introduced cow milk at less than 3 months of age, $3.8 \%$ claimed to have introduced at 3-5 months, $29.8 \%$ at 6 months, $53.2 \%$ at 6 months to 1 year and precisely $12.6 \%$ after 1 year. Intriguingly, $0.7 \%$ of these nursing mothers introduced tea, sweets, chocolates and soft drinks at less than 3 months, $0.7 \%$ at 3-5 months, $30.1 \%$ at 6 months, $54.2 \%$ at 6 months to 1 year and $14.3 \%$ after 1 year. Correctly $1.9 \%$ of the respondents of this study claimed to have introduced

formula foods (cerelac) at less than 3 months, 3.6\% at 3-5 months, $36.3 \%$ at 6 months, $50.6 \%$ at 6 months to 1 year and $7.6 \%$ after 1 year of age, respectively (See Table 4.12)

Table 7: What age did you introduce the following foods?

\begin{tabular}{|c|c|c|c|c|c|c|}
\hline \multirow[t]{2}{*}{$\mathbf{S} / \mathbf{N}$} & \multirow[t]{2}{*}{ Food item } & \multicolumn{5}{|l|}{ Age } \\
\hline & & $\begin{array}{l}<3 \\
\text { months } \\
\text { F }(\%)\end{array}$ & $\begin{array}{l}3-5 \\
\text { months } \\
\text { F }(\%)\end{array}$ & $\begin{array}{l}6 \\
\text { months } \\
\text { F }(\%)\end{array}$ & $\begin{array}{l}6 \text { months- } \\
1 \text { year } \\
\text { F }(\%)\end{array}$ & $\begin{array}{l}\text { After } 1 \\
\text { year } \\
\text { F }(\%)\end{array}$ \\
\hline a. & $\begin{array}{l}\text { Cereals (Pap, Rice, bread, } \\
\text { Semo) }\end{array}$ & $10(2.4)$ & $15(3.6)$ & $164(39.1)$ & $198(47.3)$ & $32(7.6)$ \\
\hline b. & $\begin{array}{l}\text { Yam, potatoes and other } \\
\text { tubers }\end{array}$ & $2(0.5)$ & $2(0.5)$ & $130(31.0)$ & $202(48.2)$ & $83(48.2)$ \\
\hline c. & Fruits/vegetables & $3(0.7)$ & $7(1.7)$ & $133(31.7)$ & $220(52.5)$ & $56(13.4)$ \\
\hline d. & Legumes/beans & $3(0.7)$ & $10(2.4)$ & $145(34.6)$ & $232(55.4)$ & $29(6.9)$ \\
\hline e. & Fish/Meat/Egg & $2(0.5)$ & $11(2.6)$ & $135(32.2)$ & $232(55.4)$ & $39(9.3)$ \\
\hline f. & Cow milk & $2(0.5)$ & $16(3.8)$ & $125(29.8)$ & $223(53.2)$ & $53(12.6)$ \\
\hline g. & $\begin{array}{l}\text { Tea, sweets, chocolates and } \\
\text { soft drinks }\end{array}$ & $3(0.7)$ & $3(0.7)$ & $126(30.1)$ & $227(54.2)$ & $60(14.3)$ \\
\hline h. & Formula foods (e.gcerelac) & $8(1.9)$ & $15(3.6)$ & $152(36.3)$ & $212(50.6)$ & $32(7.6)$ \\
\hline
\end{tabular}


ISSN: 2689-9418

Volume 4, Issue 3, 2021 (pp. 139-165)

www.abjournals.org

\section{Test of hypothesis}

Three hypotheses were tested for this study. In testing these hypotheses, Pearson correlation, linear and regression was conducted at 0.05 level of significance. The decision rule applied was that if the $p$-value computed was less or equal to the cut-off $p$-value of 0.05 , the null hypothesis will be rejected in favour of the alternative hypothesis and vice-versa.

Hypothesis 1:There is no significant difference between level of education of mother and their nutritional practice. Using ANOVA to carry out this hypothesis, p-value at 0.002 showed that there was a significant difference between level of education of mother and their nutritional practice (See table 7). This implies that the education status of the mother does mean a lot in their pattern and their practice of child feeding. Well educated mothers will probably follow nutritional information received at PHC in details than less educated mothers when feeding their under-five children. Hence we reject the null hypothesis.

Hypothesis2: There is no significant relationship between respondents' level of knowledge and their nutritional practice. The result of the correlation showed that there is a significant correlation between respondents' level of knowledge $(\mathrm{r}=0.256 ; p=0.000)$ and their nutrition practice (See table 8). Furthermore, a linear regression analysis was conducted to show the association between level of knowledge and practice. The result $\left(R=0.256 ; R^{2}=0.066\right.$; $\mathrm{B}=9.028 ; \beta=0.256 ; \mathrm{F}=29.319 ; \mathrm{p}=0.000$ ) showed that there is a significant association between the variables (See table 9). This implies that that independent variable (knowledge) contributes $6.6 \%$ to the changes occurring in the dependent variable (nutritional practice). Hence the null hypothesis is rejected.

Table 7: Relationship between Respondents knowledge, attitude, social support and self-efficacy towardsgood nutrition practice

\begin{tabular}{lll}
\hline Variable & Nutritional Practice N=419 & \\
& $\mathrm{r}$ & $\mathrm{p}$ value \\
Nutritional Knowledge & 0.256 & 0.000 \\
Attitude & 0.085 & 0.082 \\
Level of support & 0.078 & 0.111 \\
Self-efficacy & 0.341 & 0.000
\end{tabular}

Correlation is significant at $P<0.05$

Table 8: Association between Respondents level of knowledge, self-efficacy and nutritional practice

\begin{tabular}{lllllll}
\hline Variables & \multicolumn{9}{l}{ Nutrition Practice $\mathbf{N}=419$} & & & \\
& $\mathrm{R}$ & $\mathrm{R}$ square & $\mathrm{B}$ & $\beta$ eta & F-value & p-value \\
Knowledge & 0.256 & 0.066 & 9.028 & 0.256 & 29.319 & 0.000 \\
Self-efficacy & 0.341 & 0.117 & 7.396 & 0.341 & 55.041 & 0.000 \\
\hline
\end{tabular}

Regression is significant at $P<0.05$ 
ISSN: 2689-9418

Volume 4, Issue 3, 2021 (pp. 139-165)

www.abjournals.org

\section{DISCUSSION OF FINDINGS}

The mortality rate of children under the age of five years is a key indicator of a child's wellbeing, including health and nutrition status. It is also a key indicator of the extent of survival social and economic development interventions that must be implemented for the child's overall well-being (UNICEF, 2014). Reliable information has proven to be a contributory factor to good nutrition, while good nutrition plays a major role in maintaining health and balance, malnutrition still remains a treat to under-five children. The consequences of poor nutritional status of under-five children ranges from high rate of morbidity from infectious diseases and eventually mortality in extreme cases. This study therefore focused on the determinants of nutritional practices among mothers with under-five children attending selected primary health center in Abeokuta, Ogun state, Nigeria. The finding can go a long way in planning intervention to scale up the proper nutritional practice of mother with underfive children.

The respondents in this study were majorly between the ages of 27-35 years and married which is consistent with findings of Modjadji and Mashishi (2020) among mothers of underfive children attending Primary Health Care Facilities in Limpopo Province, South Africa. More than half of the study participant are self-employed while one-third are either civil servants/private organization or housewives as this is mostly common in Nigeria and by extension Africa as it is being observed in Ethiopia (Ayalew, 2015) and Bangladesh (Siddiqi, Haque\&Goni, 2011). About three quarter were of Christian faith while minority were traditional worshippers. Yoruba ethnic group was the leading ethnic much with more than three quarter of the study population falling into that category. More than half of the respondent had a level of education up to the secondary level while one-fourth of them proceeded to the tertiary level, as observed by Adeolu, Akpa, Adeolu and Aladeniyi (2016) in their study that maternal education has a strong relationship with child nutrition and child mortality. This is further consistent with the findings of Chowdhury, Rafiqul and Hossain (2010) that child nutrition and child mortality is higher among women with primary education and lower among women with higher education.

More than half of the study participant attended antenatal care sessions at least twice while majority attended postnatal sessions once which is contrary to the finding of Saka (2012) among HIV positive mothers attending a health care clinic in Municipality-Dar ES Salaam.Interestingly, half of the study participants had their deliveries at the hospital or health centers which is also contrary to the findings of Sarker, Rahman, Rahman, Hossain, Reichenbach and Mitra (2016) where home delivery with traditional birth attendants (TBAs) in rural Bangladesh was rampant, but one quarter of the respondents have never lost one or two children before. Similarly, more than half of the respondents has a household size of 3-6 people while the breadwinner's occupation majorly private workers or business owners. Mothers with under-five children in the study earn mostly less than 20,000 naira monthly, while their household income is less than 30,000 naira. In a study by Esther (2016) it was observed in the Northern part of Nigeria that majority of the study population earn below 5000 naira as their monthly income. Majority of the respondents in this study are either in middle class or lower class socioeconomic status. Ewusie, Beyene, Ahiadeke and Hamid (2017) reported that $66.4 \%$ belonged to lower class, $23.8 \%$ belong to middle class and $9.6 \%$ belong to upper class in their study. The different observation is due to different study setting. Though more than half of the respondents in this study are monogamous in family structure. 
ISSN: 2689-9418

Volume 4, Issue 3, 2021 (pp. 139-165)

www.abjournals.org

On assessing respondents' nutritional knowledge three quarter of the respondents could properly define what balanced diet is and deduced why normal nutrition is necessary for children. This is also consistent with the findings of Olatona, Adenihun, Aderibigbe and Adeniyi(2017) in Lagos among mothers with under-five children. However, only one-third of the participants were able to correctly tell how to identify energy (carbohydrate) deficiency in children. Similarly, only half of the respondents known when to accurately put a baby to breast after birth and what weaning is. Additionally, it can be deduced from the statistics used in this study that one-third of the respondents do not know the type of supplementary feeding to be given to a 6-month old child. In the same vein, one-third of the study participants do not know what precautionary steps to take while preparing supplementary food.

Although more than half could justly tell the causes of diarrhea in children but only one-third of the participants know what age solid foods can be introduced to children. The respondents level of knowledge regarding under-five nutrition was measured and the proportion of respondents with low level of nutritional knowledge is small which infer that the respondents had a moderate to high level of under-five nutritional knowledge. This is contrary to the findings of Mwita (2014) in Nairobi where low level of knowledge was reported. Knowledge is a basic factor in every field which is also supported by this study. Respondents with correct knowledge and awareness of EBF and child nutrition are more likely to practice EBF and proper IYCF (Mekuria \& Edris, 2015).

The statistics derived from mothers with under-five children on their attitudinal disposition was intriguing as an average number of the respondents affirming to the fact that ante-natal and post-natal sessions are time consuming. Similarly, precisely half of the respondents think using the traditional way (agbo) to treat their children in addition to immunization is more preferable and slightly less than half of the respondents affirm to missing their post-natal appointments because health attendants are harsh to them. Although almost half of the study participants no longer utilize PHC for either antenatal/postnatal care as they belief to have sufficient experience in child bearing.

Furthermore, this study examined the level of support mothers with under-five children get. One-third of the participants in this study claim they never get inspired by the people important to them (friends and family) to buy nutritious food for their children under the age of 5. Almost half of the study participants claim they have in no way been assisted by their mothers-in-law or anyone else to prepare nutritious meals for their children and the entire household. This finding contradict a study in Myanmar which revealed that family member support contributed to adherence to EBF by mothers (Thet, Khaing, Diamond-Smith, Sudhinaraset\&Aung, 2016).

In this study more than half of its respondents affirm that they are confident enough to take their infants to clinics for sessions and immunization, while two-third claim to comply with the counsel on six months exclusive breastfeeding for their children. Amusingly, over half of the respondents agreed that their under-five aged children consume more portions of meats and vegetables as compared to the adults, likewise more than half of the respondents in this study assert that buying nutritious food for their children within their food budgets is not an easy task. Most participants in this study find preparing nutritious food for both their families and children very difficult. However, the same proportion of participant are not confident about preparing healthy meals and selecting healthy snacks for their children and families. 
ISSN: 2689-9418

Volume 4, Issue 3, 2021 (pp. 139-165)

www.abjournals.org

Bottle feeding and hand feeding were practiced by few respondents which was in contrast to what was observed in Sudan where 59.2\% fed their children with their hands (Mohammed, 2014). The lower figure obtained from this study could be because most of the respondents have a minimum of secondary education and no longer practice traditional method of feeding. Additionally, over two-third of the respondents always wash their hands before feeding their child and also wash and sterilize feeding utensils after use. The proportion of respondents with high nutritional practice is more than two-third of the study population, therefore one can infer that majority of the respondents practice proper nutrition for their under-five children feeding.

Furthermore, the hypothesis tested in this study revealed that there is an association between respondents' level of knowledge, self-efficacy towards the practice of proper nutrition. Also these association is minimal, independent variables stand alone when correlating with the dependent variable for this study, but when put together has a significant association with the dependent variable. This study also confirmed that respondents' self-efficacy contributes most significantly to their proper nutritional practices.

Additionally, it was observed that there was that there was a significant difference between level of education of mother and their nutritional practice, implying that the education status of the mother does mean a lot in their pattern and their practice of child feeding. The study results clearly show the influence of maternal education on under-five nutrition which is contrary to other findings that have shown that lower maternal education has been shown to be associated with late initiation of breastfeeding after birth (Acharya and Khanal, 2015) and poor complementary feeding practices of children aged under 2 years, consequently affecting childhood nutritional status (Khanal, Sauer \& Zhao, 2013; Joshi, Agho, Dibley, Senarath\& Tiwari, 2012)

A study by Adhikari, Khatri, Paudel and Poudyal (2017) among under-five children in Eastern Nepal shows that poor socioeconomic status and housing conditions have contributed to the high prevalence of underweight among children aged 24 months or above however a significant difference between level of nutritional practice and the socioeconomic status of respondents was observed in this study. This change in variation might be as a result of the study setting and population while this study further implies that respondents' socioeconomic status predicts their under-five proper nutrition practices.

\section{CONCLUSION AND RECOMMENDATION}

The findings from the current study have several implications for policy, research, and practice. Comprehensive interventions which focus on educating future mothers, improving $\mathrm{MCH}$ service utilization, and improving the economic status of households are required to improve the nutritional situation of children under-five years of age. Improved feeding practices of pre-school children should be promoted. The health workers, especially midwife and nurses' also plays significant role in supporting breastfeeding practice and proper IYCF practices, help to assist in identification of women who may be at-risk in regards to initiaion of breastfeeding. It is necessary to have good communication and health education from health workers for the successful implementation of proper under-five nutritional practices, therefore training and re-training is required for them in order to have adequate and sufficient 
ISSN: 2689-9418

Volume 4, Issue 3, 2021 (pp. 139-165)

www.abjournals.org

information to pass across to mothers. The results of this study also identify that poor maternal attitude and good knowledge play key roles in the process of under-fivenutritional practice by their mothers. Thus, it is important to provide antenatal and early postpartum education and periodical breastfeeding counselling, especially for new mothers, to improve maternal attitudes and knowledge toward breastfeeding and IYCF practices. An earlier study suggested enhancing complementary feeding practice in Nigeria by focusing on women from poorer households and those less exposed to media for the better nutritional status of children. Strategies to improve the nutritional status of children include improving women's educational status and promoting regular growth monitoring practices. These provide an opportunity for counseling mothers about their children's nutritional needs and feeding practices. Furthermore, long-term strategies for improvement of economic status such as homestead food production, kitchen garden, and income-generating activities may also improve the child caring and feeding practices, which can impact nutritional status of children. Similarly, adequate health seeking practices during pregnancy may reduce the chance of low birth weight or preterm babies and if babies are born smaller than average size, more postnatal care, and extra care for such babies may minimize the possibility of being underweight in later months. Based on the findings, the following recommendations are being made to promote proper under-5 nutrition:

1. Continued training and re-training of those providing maternal and child health services to give simple and appropriate breastfeeding and IYCF education to expectant and nursing mothers so as to sustain the current level of knowledge.

2. There should be active involvement of the media in dissemination of IYCF information through more collaboration between the health sector, the mass media and the communities.

3. Breast feeding and IYCF education should be targeted at young and nulliparous mothers, and other significant others such as husbands and mothers-in-law.

4. The baby friendly hospital initiative concept should be expanded beyond government health facilities to privately owned hospitals, and the communities.

5. Food demonstration classes during antenatal and postnatal clinics to help mothers acquire nutritional skills should be intensified.

\section{REFERENCES}

Adeolu, M., Akpa, O., Adeolu, A., \&Aladeniyi, I. O. (2016). Environmental and socioeconomic determinants of child mortality: evidence from the 2013 Nigerian demographic health survey. Am J Public Health Res, 4(4), 134-141.

Adepoju, A. B., \& Johnson, A. T. (2020). Home Grown School Feeding Program in Nigeria: Its Nutritional Value and Anthropometry Assessment of School Age Children in Ilaro, Ogun State.The Federal Polytechnic Ilaro Journal of Pure and Applied Sciences (FEPIJOPAS), 2(2), 23-37.

Adikari, A. M. N. T., Sivakanesan, R. D. G. N. G., Wijesinghe, D. G. N. G., \&Liyanage, C. (2016). Assessment of nutritional status of pregnant women in a rural area in Sri Lanka. 
ISSN: 2689-9418

Volume 4, Issue 3, 2021 (pp. 139-165)

www.abjournals.org

Adinma, J. I. B., Umeononihu, O. S., \&Umeh, M. N. (2017). Maternal nutrition in Nigeria. Tropical Journal of Obstetrics and Gynaecology, 34(2), 79-84.

Ayalew, E. (2015). The Prevalence of Stunting and Associated Factors among Children Age 6-59 Months at Mizan-Aman Town, Bench Maji Zone, SNNPR Region, Ethiopia, 2015 (Doctoral dissertation, Addis Ababa University).

Banerjee, B. (2009). Information, education, and communication services in $\mathrm{MCH}$ care provided at an urban health center. Indian journal of community medicine: official publication of Indian Association of Preventive \& Social Medicine, 34(4), 298.

Banga, D., Baren, M., Ssonko, N. V., Sikakulya, F. K., Tibamwenda, Y., Banga, C., \&Ssebuufu, R. (2020). Comorbidities and Factors Associated with Mortality among Children under Five Years Admitted with Severe Acute Malnutrition in the Nutritional Unit of Jinja Regional Referral Hospital, Eastern Uganda. International Journal of Pediatrics, 2020.

Bashir, S. S., \& Umar, A. A. (2012). Effect of maternal literacy on nutritional status of children under 5 years of age in the Babban-Dodo community Zaria city, Northwest Nigeria. Annals of Nigerian Medicine, 6(2), 61.

Basinga, P., Gertler, P. J., Binagwaho, A., Soucat, A. L., Sturdy, J., \&Vermeersch, C. M. (2011). Effect on maternal and child health services in Rwanda of payment to primary health-care providers for performance: an impact evaluation. The Lancet, 377(9775), 1421-1428.

Bégin, F., \& Aguayo, V. M. (2017). First foods: Why improving young children's diets matter. Maternal \& child nutrition, 13, e12528.

Berisha, M., Ramadani, N., Hoxha, R., Gashi, S., Zhjeqi, V., Zajmi, D., \&Begolli, I. (2017). Knowledge, attitudes and practices of mothers in kosova about complementary feeding for infant and children 6-24 months. Medical Archives, 71(1), 37.

Edith, M., \&Priya, L. (2016). Knowledge, attitude, and practice (KAP) survey on dietary practices in prevention of malnutrition among mothers of under-five children. Manipal Journal of Nursing and Health Sciences (MJNHS), 2(2), 19-24.

Fadare, O., Amare, M., Mavrotas, G., Akerele, D., \&Ogunniyi, A. (2019). Mother's nutritionrelated knowledge and child nutrition outcomes: Empirical evidence from Nigeria. PloS one, 14(2), $\mathrm{e} 0212775$.

Gayawan, E., Adebayo, S. B., Komolafe, A. A., \&Akomolafe, A. A. (2019). Spatial distribution of malnutrition among children under five in Nigeria: a Bayesian quantile regression approach. Applied Spatial Analysis and Policy, 12(2), 229-254.

Gebre, A., Reddy, P. S., Mulugeta, A., Sedik, Y., \&Kahssay, M. (2019). Prevalence of malnutrition and associated factors among under-five children in pastoral communities of Afar Regional State, Northeast Ethiopia: a community-based cross-sectional study. Journal of nutrition and metabolism, 2019.

Grenov, B., Lanyero, B., Nabukeera-Barungi, N., Namusoke, H., Ritz, C., Friis, H., ... \&Mølgaard, C. (2019). Diarrhea, dehydration, and the associated mortality in children with complicated severe acute malnutrition: a prospective cohort study in Uganda. The Journal of pediatrics, 210, 26-33.

Grenov, B., Lanyero, B., Nabukeera-Barungi, N., Namusoke, H., Ritz, C., Friis, H., Michaelsen, K.F. and Mølgaard, C., 2019. Diarrhea, dehydration, and the associated mortality in children with complicated severe acute malnutrition: a prospective cohort study in Uganda. The Journal of pediatrics, 210, pp.26-33. 
ISSN: 2689-9418

Volume 4, Issue 3, 2021 (pp. 139-165)

Khim, K. (2016). Are health workers motivated by income? Job motivation of Cambodian primary health workers implementing performance-based financing. Global health action, 9(1), 31068

Liu, L., Oza, S., Hogan, D., Perin, J., Rudan, I., Lawn, J. E., ... \& Black, R. E. (2015). Global, regional, and national causes of child mortality in 2000-13, with projections to inform post-2015 priorities: an updated systematic analysis. The Lancet, 385(9966), 430-440.

Olatona, F. A., Adenihun, J. O., Aderibigbe, S. A., \&Adeniyi, O. F. (2017). Complementary feeding knowledge, practices, and dietary diversity among mothers of under-five children in an urban community in Lagos State, Nigeria. International Journal of MCH and AIDS, 6(1), 46.

Otekunrin, O. A., Otekunrin, O. A., Sawicka, B., \&Ayinde, I. A. (2020). Three decades of fighting against hunger in Africa: Progress, challenges and opportunities. World Nutrition, 11(3), 86-111.

Rhoda, D. A., Wagai, J. N., Beshanski-Pedersen, B. R., Yusafari, Y.,Sequeira, J., Hayford, K., Brown, D.W., Danovaro-Holliday, M.C., Braka, F., Ali, D., Shuaib, F., \& Ryman, T. K. (2020). Combining cluster surveys to estimate vaccination coverage: Experiences from Nigeria's multiple indicator cluster survey/national immunization coverage survey (MICS/NICS), 2016-17. Vaccine, 38(39), 6174-6183.

Thet, M. M., Khaing, E. E., Diamond-Smith, N., Sudhinaraset, M., Oo, S., \& Aung, T. (2016). Barriers to exclusive breastfeeding in the Ayeyarwaddy Region in Myanmar: Qualitative findings from mothers, grand-mothers, and husbands. Appetite, 96, 62-6

United Nations Children's Fund Levels and trends in child mortality, Report 2014; New York, NY, 2014.

Vakili, R., EmamiMoghadam, Z., Khademi, G., Vakili, S., \&Saeidi, M. (2015). Child mortality at different world regions: A comparison review. International Journal of Pediatrics, 3(4.2), 809-816.

WHO (2016). GUIDELINE; Updates on HIV and infant feedingThe duration of breastfeeding and support from health services to improve feeding practices among mothers living with HIV. WHO Library Cataloguing-in-Publication Data

Yohannes, B., Ejamo, E., Thangavel, T., \&Yohannis, M. (2018). Timely initiation of complementary feeding to children aged 6-23 months in rural Soro district of Southwest Ethiopia: a cross-sectional study. BMC pediatrics, 18(1), 1-7. 